\title{
Suppression of $\mathrm{OH}$ Generation from the Photo-Fenton Reaction in the Presence of alpha-Pinene Secondary Organic Aerosol Material
}

\author{
Rachel F. Hems, Jeremy S. Hsieh, Mark A. Slodki, Shouming \\ Zhou, Jonathan P.D. Abbatt
}

Version Post-print/accepted manuscript

Citation Hems, R.F., Hsieh, J.S., Slodki, M.A., Zhou, S., Abbatt, J.P.D., 2017.

(published version) Suppression of $\mathrm{OH}$ Generation from the Photo-Fenton Reaction in the Presence of alpha-Pinene Secondary Organic Aerosol Material. Environ. Sci. Technol. Lett. 4, 439-443.

https://doi.org/10.1021/acs.estlett.7b00381.

Publisher's Statement This document is the Accepted Manuscript version of a Published Work that appeared in final form in Environmental Science \& Technology Letters, copyright (C) American Chemical Society after peer review and technical editing by the publisher. To access the final edited and published work see https://pubs.acs.org/doi/10.1021/acs.estlett.7b00381.

How to cite TSpace items

Always cite the published version, so the author(s) will receive recognition through services that track citation counts, e.g. Scopus. If you need to cite the page number of the author manuscript from TSpace because you cannot access the published version, then cite the TSpace version in addition to the published version using the permanent URI (handle) found on the record page.

This article was made openly accessible by $U$ of $T$ Faculty. Please tell us how this access benefits you. Your story matters. 
Suppression of $\mathrm{OH}$ Generation from the Photo-Fenton Reaction in the Presence of $\alpha$-Pinene

2 Secondary Organic Aerosol Material

3 Rachel F. Hems*, Jeremy S. Hsieh, Mark A. Slodki, Shouming Zhou, Jonathan P.D. Abbatt

4 Department of Chemistry, University of Toronto, 80 St. George Street, M5S 3H6, Toronto,

5 Canada

ABSTRACT in cloud and fog water, a high dissolved organic content, especially of secondary organic aerosol (SOA) material, may affect $\mathrm{OH}$ production from this mechanism. The relative production of $\mathrm{OH}$ was measured for Fenton and Photo-Fenton reactions with $\mathrm{H}_{2} \mathrm{O}_{2}$ and Fenton-like and Photo-

11 Fenton-like reactions with $\alpha$-pinene ozonolysis SOA material, under cloud water relevant conditions ( $5 \mu \mathrm{M}$ iron, $45 \mu \mathrm{M} \mathrm{H}_{2} \mathrm{O}_{2}$, and $1500 \mu \mathrm{M}$ SOA). It is demonstrated that generation of $\mathrm{OH}$ radicals from Photo-Fenton chemistry can be significantly suppressed by addition of $\alpha$ pinene SOA material, where the $\mathrm{OH}$ yield for solutions containing $\mathrm{H}_{2} \mathrm{O}_{2}$ and $\mathrm{SOA}$ material together was decreased by a factor of 6 compared to that when only $\mathrm{H}_{2} \mathrm{O}_{2}$ was present, likely due to complexation by carboxylic acids (such as pinonic acid). When SOA is examined without additional $\mathrm{H}_{2} \mathrm{O}_{2}$ present, $\mathrm{OH}$ is generated by Photo-Fenton chemistry but at a lower rate than for Photo-Fenton chemistry with $\mathrm{H}_{2} \mathrm{O}_{2}$ alone. Without taking into account this suppression by SOA material, generation of $\mathrm{OH}$ by Photo-Fenton chemistry may be overestimated. Furthermore, the suppression of Photo-Fenton chemistry in aqueous organic aerosol may be enhanced with greater SOA material concentration.

\section{INTRODUCTION}

Iron and hydrogen peroxide are routinely measured at micromolar to hundreds of micromolar levels in cloud and fog water, ${ }^{1-5}$ and consequently the Fenton reaction between 25 iron(II) and hydrogen peroxide $\left(\mathrm{H}_{2} \mathrm{O}_{2}\right)$ can be a significant source of hydroxyl $(\mathrm{OH})$ radicals in the condensed phase. ${ }^{6}$ The Fenton reaction (Reaction 1) has been known since the late $1800^{9}{ }^{7}$ 27 and has been used for many years as a technology to remove organic contaminants in water, ${ }^{8,9}$ 28 but has only recently been investigated in atmospheric aerosols and cloud droplets. ${ }^{10-15}$ Fentonlike reactions have also been observed with small organic hydroperoxides $(\mathrm{ROOH})$ in place of 
$\mathrm{H}_{2} \mathrm{O}_{2}{ }^{10}$ under cloud droplet conditions and it has been proposed that larger, more complex organic hydroperoxides will also participate in this chemistry as shown below:

$$
\begin{aligned}
\mathrm{Fe}^{2+}+\mathrm{H}_{2} \mathrm{O}_{2} & \rightarrow \mathrm{Fe}^{3+}+\mathrm{OH}+\mathrm{OH}^{-}(1) \\
\mathrm{Fe}^{2+}+\mathrm{ROOH} & \rightarrow \mathrm{Fe}^{3+}+\mathrm{OH}+\mathrm{RO}^{-}(2 a) \\
& \rightarrow \mathrm{Fe}^{3+}+\mathrm{RO}^{\cdot}+\mathrm{OH}^{-}(2 \mathrm{~b})
\end{aligned}
$$

Organic hydroperoxides may produce either hydroxyl $(\mathrm{OH})$ or alkoxyl $(\mathrm{RO})$ radicals (Reactions $2 \mathrm{a}$ and $\mathrm{b}$ ). While for small hydroperoxides, methyl- and ethyl-hydroperoxide, the Fenton reaction favours the formation of the alkoxyl radical, ${ }^{10}$ it is unknown whether larger, more complex hydroperoxides will also favour alkoxyl radical formation. The presence of ultraviolet (UV) and visible light drives Photo-Fenton chemistry, which reduces iron(III) to iron(II), catalysing the Fenton reaction as well as producing additional $\mathrm{OH}$ radicals: ${ }^{16,17}$

$$
\mathrm{Fe}^{3+}\left(\mathrm{OH}^{-}\right)+h v \rightarrow \mathrm{Fe}^{2+}+\mathrm{OH}(3)
$$

In ambient cloud droplets and aerosol particles which contain copper, iron(III) may also be reduced through redox coupling with copper(I), thereby providing a dark mechanism for recycling of iron(II) for the Fenton reaction. ${ }^{18,19}$

Fenton and Photo-Fenton chemistry may also take place in aqueous aerosols as they can also contain the necessary precursors ${ }^{20,21}$ and in some cases may have higher concentrations of iron and hydrogen peroxide than in cloud droplets. ${ }^{22}$ The production of $\mathrm{OH}$ radicals from this chemistry provides an alternate route of oxidation within the condensed phase and can contribute to aerosol aging.

Secondary organic aerosol (SOA) material can be a significant component of ambient aerosol and of the organic content in cloud water. ${ }^{23}$ When dissolved in the aqueous phase, SOA material can give rise to $\mathrm{H}_{2} \mathrm{O}_{2}$ (approximately $3 \%$ by mole for $\alpha$-pinene SOA). ${ }^{24}$ Peroxide functional groups (ROOR and $\mathrm{ROOH}$ ) have been proposed to form readily in autoxidation reactions which lead to SOA formation ${ }^{25}$ and can also form through condensed phase reactions, making them abundant in SOA. ${ }^{24,26-30}$ Fenton chemistry has been observed to occur with laboratory generated SOA material and can be an important source of $\mathrm{OH}$ radicals. ${ }^{14}$ In addition, SOA contains many carboxylic acid functional groups, which have been reported to complex 
with iron and either increase or decrease the rate of Fenton reaction. ${ }^{31-33}$ Further OH production may arise from direct photolysis of iron - acid complexes, ${ }^{33,34}$ or direct photolysis of $\mathrm{H}_{2} \mathrm{O}_{2}$ and organic hydroperoxides. ${ }^{35-37}$ Recently, production of $\mathrm{OH}$ radicals from photolysis of SOA material has been observed, which was attributed to photolysis of hydroperoxides. ${ }^{24}$ Although these reactions can generate $\mathrm{OH}$ radicals under aqueous conditions, the Photo-Fenton-like reaction with SOA has not been explored and has the potential to generate even more $\mathrm{OH}$ and result in greater organic oxidation.

This study investigates $\mathrm{OH}$ radical formation from Fenton-like and Photo-Fenton-like reactions with $\alpha$ - pinene SOA material under simulated cloud water conditions. OH production was measured using benzoic acid as a radical trap ${ }^{38,39}$ and analysed offline with HPLC. Comparison to the classic Fenton and Photo-Fenton reactions (i.e. with $\mathrm{H}_{2} \mathrm{O}_{2}$ ) was used to determine whether SOA material enhances or diminishes the production of $\mathrm{OH}$.

MATERIALS AND METHODS

\section{Dark-Fenton and Photo-Fenton Reactions}

All Fenton reactions (referred to as Dark-Fenton) were conducted in amber glass vessels to reduce ambient light from impacting the reaction. Photo-Fenton reactions were conducted in $10 \mathrm{~mL}$ quartz reaction vessels in a Suntest CPS solar simulator (Atlas) with a xenon lamp, which has an emission spectrum in the actinic range ( 290-800 nm) (See Figure S1), to initiate photocatalyzed reactions. Iron was supplied from a stock solution of iron (II) sulfate heptahydrate $\left(\mathrm{FeSO}_{4} \cdot 7 \mathrm{H}_{2} \mathrm{O}\right.$, Sigma Aldrich) to obtain a concentration of $5 \mu \mathrm{M}$ in the reaction vessel. Either $\mathrm{H}_{2} \mathrm{O}_{2}$ ( $\geq 30 \%$ wt, Sigma-Aldrich), cis-pinonic acid (98\%, Sigma Aldrich), or water soluble $\alpha-$ pinene SOA material (described in supporting information) was added as the reaction partner. SOA constituents were assumed to have an average molecular weight of $200 \mathrm{~g} \mathrm{~mol}^{-124,40}$ to convert mass concentration to mole concentration of SOA. The final concentration of $\mathrm{H}_{2} \mathrm{O}_{2}$, pinonic acid, and SOA were $45 \mu \mathrm{M}, 1500 \mu \mathrm{M}$, and $1500 \mu \mathrm{M}$ respectively. It is reported that aqueous $\alpha$-pinene SOA contains up to $3 \%$ by mole $\mathrm{H}_{2} \mathrm{O}_{2}{ }^{24}$ (such that $1500 \mu \mathrm{M}$ SOA would give rise to as much as $45 \mu \mathrm{M} \mathrm{H}_{2} \mathrm{O}_{2}$ ). Concentrations were chosen to be within the range of realistic cloud water conditions, where dissolved iron concentrations are generally measured at low micromolar levels $(0.1-10 \mu \mathrm{M})^{5}$ and $\mathrm{H}_{2} \mathrm{O}_{2}$ concentrations range from $1-100 \mu \mathrm{M} .{ }^{4}$ SOA concentrations in cloud water are difficult to estimate, but using a similar estimation as Badali $e t$ 
$a l .{ }^{24}$, if the SOA concentration is $1500 \mu \mathrm{M}$ the approximate corresponding cloud water dissolved organic carbon (DOC) concentration would be on the order of $100 \mathrm{mg} \mathrm{L}^{-1}$. Although on the high end of measured DOC concentrations in cloud water, $100 \mathrm{mg} \mathrm{L}^{-1}$ DOC would be representative of a polluted environment. ${ }^{41}$ The $\mathrm{pH}$ of reaction solutions was unbuffered, but remained approximately constant over the course of the reaction between $3.5-4.5$.

The reaction solutions were sampled before reaction and at 30 and 60 minutes after initiating reaction. The reaction was considered initiated once all reactants were added to the solution, or once the solutions began irradiation in the case of the Photo-Fenton reactions.

\section{Hydroxyl radical production analysis}

Benzoic acid (Sigma-Aldrich) was added to the reaction solution as a hydroxyl radical trap at a concentration of $1 \mathrm{mM}$. A higher concentration of benzoic acid ( $3 \mathrm{mM}$ or $5 \mathrm{mM})$ was tested to ensure all $\mathrm{OH}$ radicals were indeed being captured during reaction and that the SOA material or pinonic acid was not scavenging $\mathrm{OH}$ (Figures S3 and S4). OH production was quantified by the formation of para-hydroxybenzoic acid (PHBA), whose yield is 0.18 from the reaction of benzoic acid with $\mathrm{OH} .{ }^{38}$ Comparing the $\mathrm{OH}$ produced after 60 minutes of reaction to the total molar concentration of either $\mathrm{H}_{2} \mathrm{O}_{2}$ or $\mathrm{SOA}$, we calculated the $\mathrm{OH}$ molar yield for each reaction (Table 1).

Samples were analysed for benzoic acid and hydroxybenzoic acids with a PerkinElmer Series 200 HPLC with a Shimadzu UV-Vis detector similar to the method in Badali et al. ${ }^{24}$ The complete instrumental parameters are included in the supporting information.

It should be noted that the photolysis of iron (II) sulfate in the presence of benzoic acid produced a small and reproducible concentration of PHBA, which increased with increasing iron concentration. The production of PHBA from this process was accounted for and subtracted from the measured concentration of PHBA from Photo-Fenton reactions ( $<30 \%$ of total signal). Formation of PHBA from direct photolysis of $\mathrm{H}_{2} \mathrm{O}_{2}$ and/or SOA material (i.e. no iron present for Fenton chemistry) was also accounted for (<13\% of total signal).

\section{RESULTS AND DISCUSSION}


Dark-Fenton and Photo-Fenton reactions were confirmed to occur with hydrogen peroxide under our experimental conditions. As expected, the Dark-Fenton reaction (Figure 1) produced fewer $\mathrm{OH}$ radicals than the equivalent Photo-Fenton reaction with $\mathrm{H}_{2} \mathrm{O}_{2}$ (Figure 2), where the $\mathrm{OH}$ yield (in terms of $\mathrm{H}_{2} \mathrm{O}_{2}$ ) at 60 minutes for the Photo-Fenton reaction was 6 times greater than the Dark-Fenton reaction (Table 1). Notably, the $\mathrm{OH}$ production from both the Dark-Fenton and Photo-Fenton chemistry appears to behave non-linearly as a function of time, although we have a limited number of measured time points. This suggests that there is a reduction in the rates of these reactions as the concentrations of $\mathrm{Fe}(\mathrm{II})$ and $\mathrm{H}_{2} \mathrm{O}_{2}$ decrease over time. This is expected in the Dark-Fenton reaction where the reaction is limited by reduction of $\mathrm{Fe}(\mathrm{III})$ back to $\mathrm{Fe}(\mathrm{II})$, as well as loss of $\mathrm{H}_{2} \mathrm{O}_{2}$ over time. The Photo-Fenton reaction can similarly be limited by reduction of $\mathrm{Fe}(\mathrm{III})$ if iron complexes that form are not photo-active, to participate in the Photo-Fenton reaction (Reaction 3). ${ }^{2,11,31}$

The Dark-Fenton-like reaction with SOA material produced the lowest amount of $\mathrm{OH}$ (Figure 1) (0.06\% molar yield, relative to SOA), which suggests that this is not an important source. This $\mathrm{OH}$ yield is significantly smaller than what was concluded by Tong et al., ${ }^{14}$ who found an $\mathrm{OH}$ molar yield of $1 \%$ from the Dark-Fenton reaction with a similar amount of $\alpha$ pinene SOA material $(1500 \mu \mathrm{M})$. However, the relative iron concentration used was much higher (15 to 50 times higher iron concentrations than this study), which could explain the observed differences in $\mathrm{OH}$ production.

To explore the effect that SOA has on $\mathrm{OH}$ generation from the Photo-Fenton reaction, a known amount of SOA $(1500 \mu \mathrm{M})$ was added to the $\mathrm{H}_{2} \mathrm{O}_{2}$ solution $(45 \mu \mathrm{M})$. Indeed, $\mathrm{OH}$ was observed to form from Photo-Fenton chemistry with both $\mathrm{H}_{2} \mathrm{O}_{2}$ and SOA material present (Figure 2). However, the $\mathrm{OH}$ molar yield (in terms of $\mathrm{H}_{2} \mathrm{O}_{2}$ concentration) is 6 times less than that of the Photo-Fenton reaction with $\mathrm{H}_{2} \mathrm{O}_{2}$ alone (Table 1). Additionally, the $\mathrm{OH}$ produced does not appear to increase any further between 30 and 60 minutes of reaction time. This indicates that the SOA material acts to suppress $\mathrm{OH}$ formation from the Photo-Fenton reaction. Carboxylic acids, which are commonly found in aqueous SOA material, are known to complex readily with both $\mathrm{Fe}(\mathrm{II})$ and $\mathrm{Fe}(\mathrm{III})$ species and possibly alter the rate of the Photo-Fenton reaction. ${ }^{31}$ While certain carboxylic acids, like oxalic acid, can increase the effectiveness of Photo-Fenton chemistry through photo-reduction of iron and production of additional $\mathrm{H}_{2} \mathrm{O}_{2}$, 
others, like malic, malonic, or formic acid, can inhibit photo-reduction of iron and reduce the amount of free iron available for reaction with $\mathrm{H}_{2} \mathrm{O}_{2} \cdot{ }^{31-33,42,43}$ Major products in $\alpha$-pinene SOA (and other terpene derived SOA) are complex carboxylic acids ${ }^{44,45}$, whose effect on Fenton chemistry has not previously been investigated.

To investigate the effect of a major carboxylic acid present in $\alpha$-pinene SOA, pinonic acid $(1500 \mu \mathrm{M})$ was used in place of the SOA material in the Photo-Fenton reaction with $\mathrm{H}_{2} \mathrm{O}_{2}$. A similar suppression of the total $\mathrm{OH}$ production is observed compared to the case with $\mathrm{H}_{2} \mathrm{O}_{2}$ alone (Figure 2). The $\mathrm{OH}$ molar yield (in terms of $\mathrm{H}_{2} \mathrm{O}_{2}$ concentration) after 60 minutes of reaction with pinonic acid added is 3 times less than that of the reaction with $\mathrm{H}_{2} \mathrm{O}_{2}$ alone (Table 1). Although the $\mathrm{OH}$ suppression by pinonic acid is not as large as with the $\alpha$-pinene SOA, it indicates that this one component can have a similar suppression effect on the Photo-Fenton reaction as can a more complex mixture. It also gives evidence for iron complexation that leads to a reduction in the rate of the Photo-Fenton reaction. Further evidence of pinonic acid complexation by measurement of the UV-Vis spectrum is shown in Figure S5. It is likely that other carboxylic acids found in $\alpha$-pinene SOA, such as pinic or norpinonic acid, ${ }^{45}$ may behave similarly.

Interestingly, the Photo-Fenton-like reaction with SOA material showed an enhanced production of $\mathrm{OH}$ compared to the Photo-Fenton reaction with $\mathrm{H}_{2} \mathrm{O}_{2}$ and $\mathrm{SOA}$ material together, however still approximately 3 times less than the Photo-Fenton reaction with $\mathrm{H}_{2} \mathrm{O}_{2}$ alone (Figure 2). The chemistry of these systems is complex and when $\mathrm{H}_{2} \mathrm{O}_{2}$ and SOA are added together, their individual $\mathrm{OH}$ production is apparently not additive perhaps resulting from competition for available iron or aqueous chemistry between the SOA material and $\mathrm{H}_{2} \mathrm{O}_{2}$, for example reaction of $\mathrm{H}_{2} \mathrm{O}_{2}$ with aldehydes to form $\alpha$-hydroxyhydroperoxides. ${ }^{46}$

The reduced $\mathrm{OH}$ production in the Photo-Fenton-like reaction with SOA material compared to the Photo-Fenton reaction with $\mathrm{H}_{2} \mathrm{O}_{2}$ could arise from the SOA material complexing the iron species, as discussed above. Another possibility is that the $\mathrm{H}_{2} \mathrm{O}_{2}$ concentration is overestimated in aqueous SOA, with the assumption that $3 \%$ of water soluble SOA material would give rise to $\mathrm{H}_{2} \mathrm{O}_{2}{ }^{24}$ This $3 \%$ value is likely an upper limit, which may also include response from dissolved organic hydroperoxides that do not participate significantly in 
the Photo-Fenton chemistry and/or do not generate significant $\mathrm{OH}$, as was observed to occur for methyl- and ethyl-hydroperoxides which give rise to alkoxyl radicals ( $\mathrm{RO}^{*}$, reaction $\left.2 \mathrm{~b}\right) .^{10}$

We note that the SOA material or pinonic acid could in theory also quench $\mathrm{OH}$ production by providing a reactive sink for any $\mathrm{OH}$ radicals produced. However, this effect was ruled out by increasing the benzoic acid concentration to confirm that it was the major sink for $\mathrm{OH}$ (Figures S3 and S4). No significant increase in $\mathrm{OH}$ production was observed at higher benzoic acid concentration verifying that $1 \mathrm{mM}$ sufficiently captures $\mathrm{OH}$ production from this reaction.

An overall conclusion from this work is that, $\alpha$-pinene SOA material does not participate significantly in the Dark-Fenton and Photo-Fenton reactions to act as an additional source of $\mathrm{OH}$ radicals in the condensed phase. It appears instead that SOA reduces the yield of $\mathrm{OH}$ from Photo-Fenton reactions due at least in part to the presence of carboxylic acids like pinonic acid.

\section{Atmospheric Implications}

Generation mechanisms of $\mathrm{OH}$ in cloud droplets have traditionally included photolysis of $\mathrm{H}_{2} \mathrm{O}_{2}$, nitrate, and nitrite, and Dark-Fenton and Photo-Fenton chemistry with $\mathrm{H}_{2} \mathrm{O}_{2}$. Photolysis of organic hydroperoxides has also been identified as an $\mathrm{OH}$ source. ${ }^{24}$ Recently, Tong et al. suggested that decomposition of SOA material and Dark-Fenton-like chemistry with SOA material may also be significant sources of $\mathrm{OH}$ in cloud droplets. ${ }^{14}$ This work shows that PhotoFenton-like chemistry with $\alpha$-pinene SOA material can also generate a significant amount of $\mathrm{OH}$, more than Dark-Fenton-like chemistry with SOA and direct photolysis of SOA alone. The overall $\mathrm{OH}$ production will therefore depend greatly on the chemical composition of the cloud droplets as well as the degree of illumination. This has implications for the oxidizing capacity of the droplets, notably for aging of organic species.

$\alpha$-pinene SOA material also acted to suppress $\mathrm{OH}$ production from Photo-Fenton chemistry with $\mathrm{H}_{2} \mathrm{O}_{2}$. If this process is not considered, $\mathrm{OH}$ production from Photo-Fenton chemistry may be overestimated. Given that our reaction conditions are within the range relevant to cloud water, it is likely that Photo-Fenton chemistry is suppressed in cloud droplets that contain terpene-derived SOA material, or in aqueous SOA particles with an even higher organic concentration. Therefore, the Dark-Fenton and Photo-Fenton reactions may be of greater 
importance for cloud water with lower organic content. More concentrated aqueous aerosols may have greater contribution of $\mathrm{OH}$ production from the Fenton and Photo-Fenton reactions compared to cloud water, but may also have greater suppression effects if significant SOA material is present. While suppression by SOA material occurs, the production rate of $\mathrm{OH}$ (assuming linear production of $\mathrm{OH}$ ) from Photo-Fenton and Photo-Fenton-like reactions measured here $\left(10^{-9} \mathrm{M} \mathrm{s}^{-1}\right)$ is of similar order of magnitude to those measured for the total $\mathrm{OH}$ production rate in cloud and fog water $\left(10^{-9} \mathrm{M} \mathrm{s}^{-1}\right) \cdot{ }^{47}$ And so, Photo-Fenton reactions may still be significant, despite the suppression effects, with other condensed phase $\mathrm{OH}$ sources in cloud water.

\section{Acknowledgements}

The authors thank the Natural Sciences and Engineering Research Council of Canada and the University of Toronto Centre for Global Chance Science Summer Intern Programme for funding.

\section{ASSOCIATED CONTENT}

\section{Supporting Information}

Supporting Information Available: Additional text and figures showing the solar simulator spectrum, SOA generation method, reaction of benzoic acid with OH radicals, HPLC analysis method, and supplementary results including increased benzoic acid concentration and UV-Vis spectrum of iron and pinonic acid complexation.

\section{AUTHOR INFORMATION}

\section{Corresponding Author}

*E-mail: rachel.hems@ mail.utoronto.ca Telephone: 1-416-946-7359

\section{REFERENCES}

(1) Sakugawa, H.; Kaplan, I. R.; Tsai, W.; Cohen, Y. Atmospheric hydrogen peroxide. Environ. Sci. Technol. 1990, 10 (10), 29-32.

(2) Arakaki, T.; Faust, B. C. Sources, sinks, and mechanisms of hydroxyl radical (OH) photoproduction and consumption in authentic acidic continental cloud waters from Whiteface Mountain, New York: The role of the Fe(r) (r = II, III) photochemical cycle. $J$. 
Geophys. Res. 1998, 103, 3487-3504.

231

232

233

234

(3) Siefert, R. L.; Pehkonen, S. O.; Erel, Y.; Hoffmann, M. R. Iron photochemistry of aqueous suspensions of ambient aerosol with added organic acids. Geochim. Cosmochim. Acta 1994, 58 (15), 3271-3279.

(4) Jackson, A. V; Hewitt, C. N. Atmosphere Hydrogen Peroxide and Organic Hydroperoxides: A Review. Crit. Rev. Environ. Sci. Technol. 1999, 29 (2), 175-228.

(5) Deguillaume, L.; Leriche, M.; Desboeufs, K.; Mailhot, G.; George, C.; Chaumerliac, N. Transition metals in atmospheric liquid phases: Sources, reactivity, and sensitive parameters. Chem. Rev. 2005, 105 (9), 3388-3431.

(6) Deguillaume, L.; Leriche, M.; Chaumerliac, N. Impact of radical versus non-radical pathway in the Fenton chemistry on the iron redox cycle in clouds. Chemosphere 2005, 60 (5), 718-724.

(7) Fenton, H. J. H. Oxidation of Tartaric Acid in presence of Iron. J. Chem. Soc. Trans. 1894, 65, 899-910.

(8) Ebrahiem, E. E.; Al-Maghrabi, M. N.; Mobarki, A. R. Removal of organic pollutants from industrial wastewater by applying photo-Fenton oxidation technology. Arab. J. Chem. 2013, 10, S1674-S1679.

(9) Kavitha, V.; Palanivelu, K. The role of ferrous ion in Fenton and photo-Fenton processes for the degradation of phenol. Chemosphere 2004, 55 (9), 1235-1243.

(10) Chevallier, E.; Jolibois, R. D.; Meunier, N.; Carlier, P.; Monod, A. "Fenton-like" reactions of methylhydroperoxide and ethylhydroperoxide with $\mathrm{Fe} 2+$ in liquid aerosols under tropospheric conditions. Atmos. Environ. 2004, 38 (6), 921-933.

(11) Nguyen, T. B.; Coggon, M. M.; Flagan, R. C.; Seinfeld, J. H. Reactive uptake and photofenton oxidation of glycolaldehyde in aerosol liquid water. Environ. Sci. Technol. 2013, 47 (9), 4307-4316.

(12) Holmes, B. J.; Petrucci, G. A. Oligomerization of levoglucosan by Fenton chemistry in proxies of biomass burning aerosols. J. Atmos. Chem. 2007, 58 (2), 151-166. 
(13) Daumit, K. E.; Carrasquillo, A. J.; Sugrue, R. A.; Kroll, J. H. Effects of Condensed-Phase Oxidants on Secondary Organic Aerosol Formation. J. Phys. Chem. A 2016, 120 (9), $1386-1394$.

(14) Tong, H.; Arangio, A. M.; Lakey, P. S. J.; Berkemeier, T.; Liu, F.; Kampf, C. J.; Brune, W. H.; Poschl, U.; Shiraiwa, M. Hydroxyl radicals from secondary organic aerosol decomposition in water. Atmos. Chem. Phys. 2016, 16 (3), 1761-1771.

(15) Al-Abadleh, H. A. Review of the bulk and surface chemistry of iron in atmospherically relevant systems containing humic-like substances. RSC Adv. 2015, 5 (57), 45785-45811.

(16) Daumit, K. E.; Carrasquillo, A. J.; Hunter, J. F.; Kroll, J. H. Laboratory studies of the aqueous-phase oxidation of polyols: submicron particles vs. bulk aqueous solution. Atmos. Chem. Phys. 2014, 14, 10773-10784.

(17) Faust, B. C.; Hoigné, J. Photolysis of Fe (III)-hydroxy complexes as sources of $\mathrm{OH}$ radicals in clouds, fog and rain. Atmos. Environ. Part A, Gen. Top. 1990, 24 (1), 79-89.

(18) Mao, J.; Fan, S.; Jacob, D. J.; Travis, K. R. Radical loss in the atmosphere from Cu-Fe redox coupling in aerosols. Atmos. Chem. Phys. 2013, 13 (2), 509-519.

(19) Mao, J.; Fan, S.; Horowitz, L. W. Soluble Fe in Aerosols Sustained by Gaseous HO2 Uptake. Environ. Sci. Technol. Lett. 2017, 4 (3), 98-104.

(20) Hoffmann, P.; Dedik, A. N.; Ensling, J.; Weinbruch, S.; Weber, S.; Sinner, T.; Gütlich, P.; Ortner, H. M. Speciation of iron in atmospheric aerosol samples. J. Aerosol Sci. 1996, 27 (2), 325-337.

(21) Dedik, A. N.; Hovvmannt, P.; Ensling, J. Chemical Characterization of Iron in Atmospheric Aerosols. Atmos. Environ. 1992, 26 (14), 2545-2548.

(22) Arellanes, C.; Paulson, S. E.; Fine, P. M.; Sioutas, C. Exceeding of Henry's Law by Hydrogen Peroxide Associated with Urban Aerosols. Environ. Sci. Technol. 2006, 40 (16), 4859-4866.

(23) Zhao, Y.; Hallar, A. G.; Mazzoleni, L. R. Atmospheric organic matter in clouds: Exact masses and molecular formula identification using ultrahigh-resolution FT-ICR mass 
spectrometry. Atmos. Chem. Phys. 2013, 13 (24), 12343-12362.

285

286
(24) Badali, K. M.; Zhou, S.; Aljawhary, D.; Antiñolo, M.; Chen, W. J.; Lok, A.; Mungall, E.; Wong, J. P. S.; Zhao, R.; Abbatt, J. P. D. Formation of hydroxyl radicals from photolysis of secondary organic aerosol material. Atmos. Chem. Phys. 2015, 15 (14), 7831-7840.

(25) Ehn, M.; Thornton, J. A.; Kleist, E.; Sipilä, M.; Junninen, H.; Pullinen, I.; Springer, M.; Rubach, F.; Tillmann, R.; Lee, B.; et al. A large source of low-volatility secondary organic aerosol. Nature 2014, 506 (7489), 476-479.

(26) Docherty, K. S.; Wu, W.; Lim, Y. Bin; Ziemann, P. J. Contributions of Organic Peroxides to Secondary Aerosol Formed from Reactions of Monoterpenes with O3. Environ. Sci. Technol. 2005, 39 (11), 4049-4059.

(27) Chen, X.; Hopke, P. K. Secondary organic aerosol from $\alpha$-pinene ozonolysis in dynamic chamber system. Indoor Air 2009, 19 (4), 335-345.

(28) Chen, X.; Hopke, P. K. A chamber study of secondary organic aerosol formation by limonene ozonolysis. Indoor Air 2010, 20 (4), 320-328.

(29) Wang, Y.; Kim, H.; Paulson, S. E. Hydrogen peroxide generation from $\alpha$ - and $\beta$-pinene and toluene secondary organic aerosols. Atmos. Environ. 2011, 45 (18), 3149-3156.

(30) Mertes, P.; Pfaffenberger, L.; Dommen, J.; Kalberer, M.; Baltensperger, U. Development of a sensitive long path absorption photometer to quantify peroxides in aerosol particles (Peroxide-LOPAP). Atmos. Meas. Tech. 2012, 5 (10), 2339-2348.

(31) Baba, Y.; Yatagai, T.; Harada, T.; Kawase, Y. Hydroxyl radical generation in the photofenton process: Effects of carboxylic acids on iron redox cycling. Chem. Eng. J. 2015, 277, 229-241.

(32) Ma, J.; Ma, W.; Song, W.; Chen, C.; Tang, Y.; Zhao, J.; Huang, Y.; Xu, Y.; Zang, L. Fenton degradation of organic pollutants in the presence of low-molecular-weight organic acids: Cooperative effect of quinone and visible light. Environ. Sci. Technol. 2006, 40 (2), $618-624$.

(33) Kwan, C. Y.; Chu, W. Photodegradation of 2,4-dichlorophenoxyacetic acid in various 
iron-mediated oxidation systems. Water Res. 2003, 37 (18), 4405-4412.

312

(34) Zuo, Y.; Holgne, J. Formation of hydrogen peroxide and depletion of oxalic acid in atmospheric water by photolysis of Iron(III)-oxalato complexes. Environ. Sci. Technol. 1992, 26 (5), 1014-1022.

(35) Walser, M. L.; Park, J.; Gomez, A. L.; Russell, A. R.; Nizkorodov, S. A. Photochemical aging of secondary organic aerosol particles generated from the oxidation of d-limonene. J. Phys. Chem. A 2007, 111 (10), 1907-1913.

(36) Wong, J. P. S.; Zhou, S.; Abbatt, J. P. D. Changes in Secondary Organic Aerosol Composition and Mass due to Photolysis : Relative Humidity Dependence. J. Phys. Chem. A 2015, 119 (19), 4309-4316.

(37) Epstein, S. A.; Blair, S. L.; Nizkorodov, S. A. Direct Photolysis of $\alpha$-Pinene Ozonolysis Secondary Organic Aerosol: Effect on Particle Mass and Peroxide Content. Environ. Sci. Technol. 2014, 48, 11251-11258.

(38) Anastasio, C.; Mcgregor, K. G. Chemistry of fog waters in California's Central Valley: 1. In situ photoformation of hydroxyl radical and singlet molecular oxygen. Atmos. Environ. 2001, 35, 1079-1089.

(39) Klein, G. W.; Bhatla, K.; Madhavan, V.; Schuler, R. H. Reaction of OH with Benzoic Acid. Isomer Distribution in the Radical Intermediates. J. Phys. Chem. 1975, 79 (17), $1767-1774$.

(40) Bateman, A. P.; Nizkorodov, S. A.; Laskin, J.; Laskin, A. Photolytic processing of secondary organic aerosols dissolved in cloud droplets. Phys. Chem. Chem. Phys. 2011, 13 (26), 12199-12212.

(41) Herckes, P.; Valsaraj, K. T.; Collett, J. L. A review of observations of organic matter in fogs and clouds: Origin, processing and fate. Atmos. Res. 2013, 132-133, 434-449.

(42) Kwan, C. Y.; Chu, W. The role of organic ligands in ferrous-induced photochemical degradation of 2,4-dichlorophenoxyacetic acid. Chemosphere 2007, 67 (8), 1601-1611.

(43) Thomas, D. A.; Coggon, M. M.; Lignell, H.; Schilling, K. A.; Zhang, X.; Schwantes, R. 


\section{4}

59

H.; Flagan, R. C.; Seinfeld, J. H.; Beauchamp, J. L. Real-Time Studies of Iron OxalateMediated Oxidation of Glycolaldehyde as a Model for Photochemical Aging of Aqueous Tropospheric Aerosols. Environ. Sci. Technol. 2016, 50 (22), 12241-12249.

(44) Ma, Y.; Russell, A. T.; Marston, G. Mechanisms for the formation of secondary organic aerosol components from the gas-phase ozonolysis of a-pinene. Phys. Chem. Chem. Phys. 2008, 10 (29), 4294-4312.

(45) Glasius, M.; Lahaniati, M.; Calogirou, A.; Di Bella, D.; Jensen, N. R.; Hjorth, J.; Kotzias, D.; Larsen, B. R. Carboxylic acids in secondary aerosols from oxidation of cyclic monoterpenes by ozone. Environ. Sci. Technol. 2000, 34 (6), 1001-1010.

(46) Zhao, R.; Lee, A. K. Y.; Soong, R.; Simpson, A. J.; Abbatt, J. P. D. Formation of aqueousphase $\alpha$-hydroxyhydroperoxides ( $\alpha$-HHP): Potential atmospheric impacts. Atmos. Chem. Phys. 2013, 13 (12), 5857-5872.

(47) Arakaki, T.; Anastasio, C.; Kuroki, Y.; Nakajima, H.; Okada, K.; Kotani, Y.; Handa, D.; Azechi, S.; Kimura, T.; Tsuhako, A.; et al. A general scavenging rate constant for reaction of hydroxyl radical with organic carbon in atmospheric waters. Environ. Sci. Technol. 2013, 47 (15), 8196-8203. 


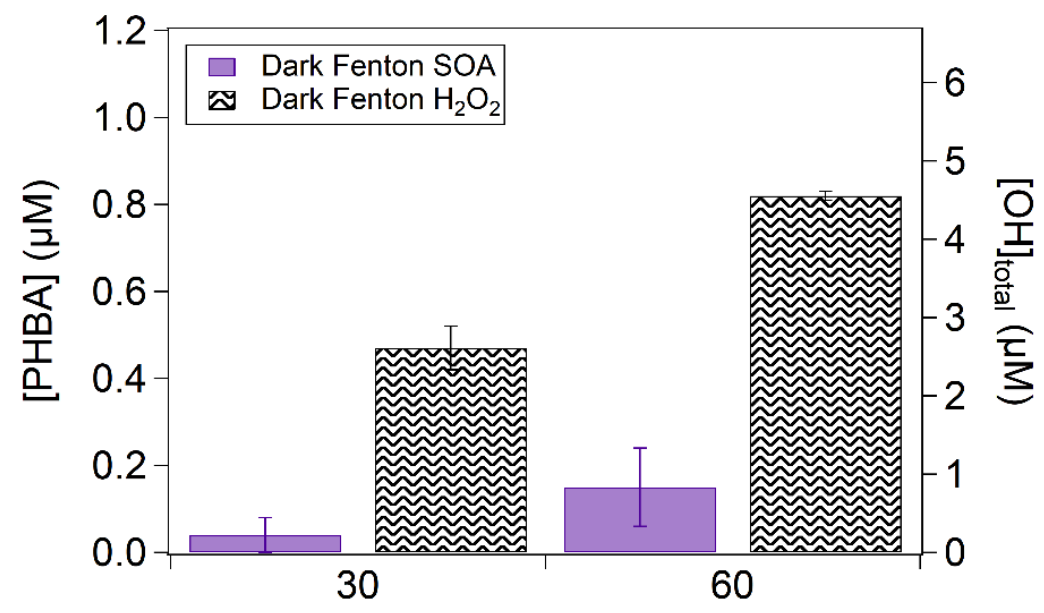

364

Reaction Time (Minutes)

Figure 1. Para-hydroxybenzoic acid (PHBA) and total $\mathrm{OH}$ formation as a function of reaction time from the Dark-Fenton reactions with $\mathrm{H}_{2} \mathrm{O}_{2}(45 \mu \mathrm{M})$ and $\alpha$-pinene SOA $(1500 \mu \mathrm{M})$. Error bars indicate propagated standard deviation from multiple $(\geq 3)$ experiments and respective control reactions.

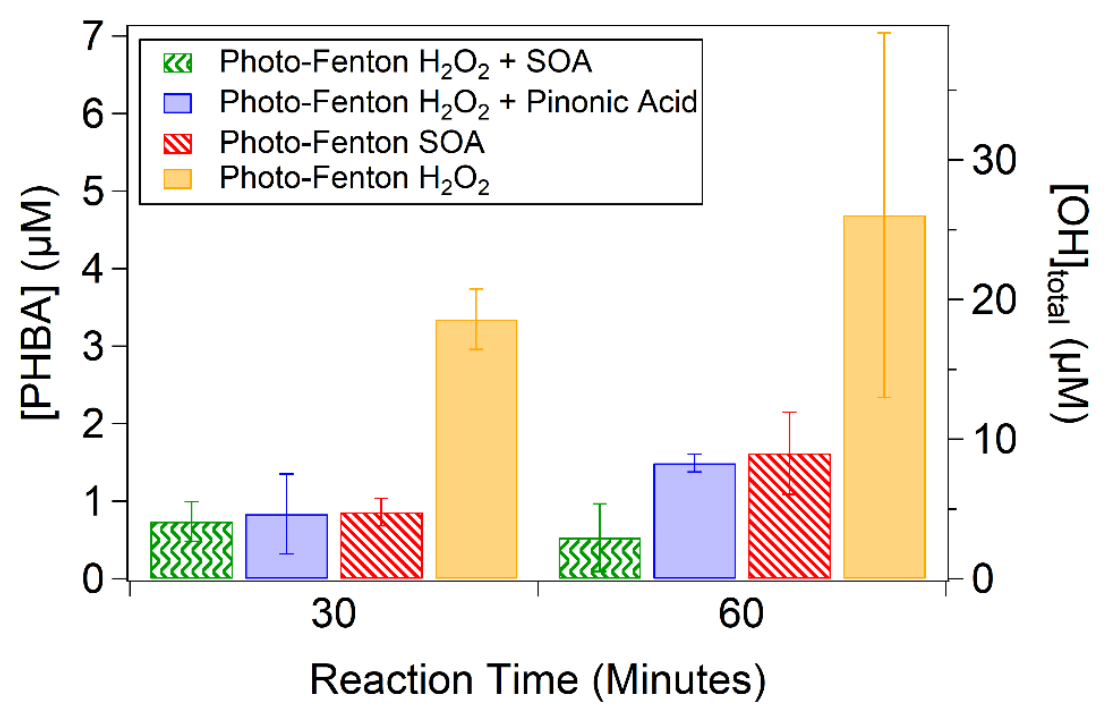

Figure 2. Para-hydroxybenzoic acid (PHBA) and total $\mathrm{OH}$ formation as a function of reaction time (time since irradiation) from the Photo-Fenton reactions with $\mathrm{H}_{2} \mathrm{O}_{2}(45 \mu \mathrm{M}), \alpha$-pinene SOA $(1500 \mu \mathrm{M})$, a mixture of $\mathrm{H}_{2} \mathrm{O}_{2}$ and pinonic acid ( $45 \mu \mathrm{M} \mathrm{H}_{2} \mathrm{O}_{2}$ and $1500 \mu \mathrm{M}$ pinonic acid), and a mixture of $\mathrm{H}_{2} \mathrm{O}_{2}$ and SOA ( $45 \mu \mathrm{M} \mathrm{H}_{2} \mathrm{O}_{2}$ and $\left.1500 \mu \mathrm{M} \mathrm{SOA}\right)$. Error bars indicate propagated standard deviation from multiple ( $\geq 3)$ experiments and respective control reactions. 
375 Table 1. Hydroxyl radical molar yields after 60 minutes of reaction from the Dark-Fenton and 376 Photo-Fenton reactions of $\mathrm{H}_{2} \mathrm{O}_{2}(45 \mu \mathrm{M})$, $\alpha$-pinene SOA $(1500 \mu \mathrm{M})$, a mixture of $\mathrm{H}_{2} \mathrm{O}_{2}$ and 377 pinonic acid (45 $\mu \mathrm{M}$ and $1500 \mu \mathrm{M}$, respectively), and a mixture of $\mathrm{H}_{2} \mathrm{O}_{2}$ with SOA (45 $\mu \mathrm{M}$ and $3781500 \mu \mathrm{M}$, respectively). $\mathrm{OH}$ molar yields are calculated from the concentration of $\mathrm{OH}$, using the 379 concentration of PHBA formed after 60 minutes (Figures 1 and 2) and the yield of PHBA, 380 compared to the starting molar concentration of either $\mathrm{H}_{2} \mathrm{O}_{2}$ or SOA. Uncertainties are the 381 standard deviation between multiple (3) experiments.

\begin{tabular}{lcc}
\hline Reaction & $\begin{array}{c}\text { OH Molar Yield (\%) } \\
\left.\text { (in terms of } \mathbf{H}_{2} \mathbf{O}_{2}\right)\end{array}$ & $\begin{array}{c}\text { OH Molar Yield (\%) } \\
\text { (in terms of SOA) }\end{array}$ \\
\hline Dark-Fenton $\mathrm{H}_{2} \mathrm{O}_{2}$ & $10.1 \pm 0.1$ & - \\
Photo-Fenton $\mathrm{H}_{2} \mathrm{O}_{2}$ & $58.2 \pm 29.0$ & - \\
Dark-Fenton SOA & - & $0.06 \pm 0.03$ \\
Photo-Fenton SOA & - & $0.60 \pm 0.22$ \\
Photo-Fenton Pinonic acid $+\mathrm{H}_{2} \mathrm{O}_{2}$ & $18.4 \pm 1.4$ & - \\
Photo-Fenton SOA $+\mathrm{H}_{2} \mathrm{O}_{2}$ & $10.2 \pm 5.4$ & $0.30 \pm 0.16$ \\
\hline
\end{tabular}

383 Table of Contents Graphic:

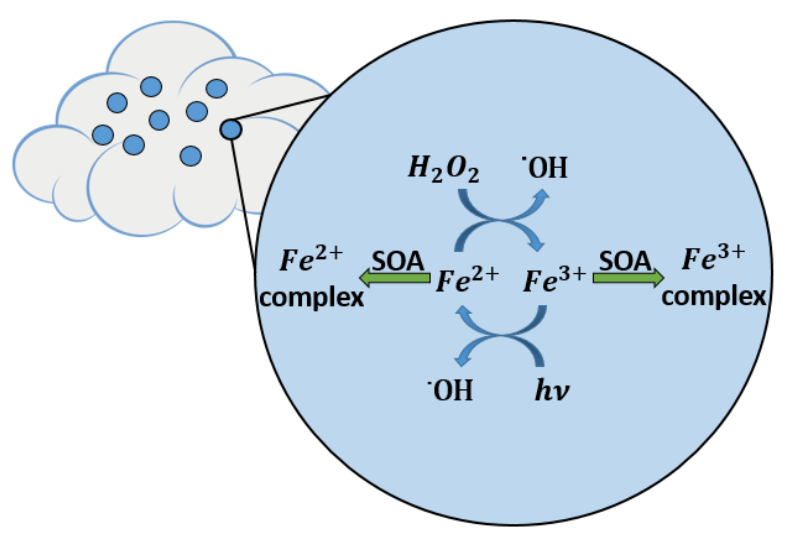


2 Suppression of $\mathrm{OH}$ Generation from the Photo-Fenton Reaction in the Presence of $\alpha$-Pinene

3 Secondary Organic Aerosol Material

4 Rachel F. Hems ${ }^{\dagger *}$, Jeremy S. Hsieh ${ }^{\dagger}$, Mark A. Slodki ${ }^{\dagger}$, Shouming Zhou ${ }^{\dagger}$, Jonathan P.D. Abbatt ${ }^{\dagger}$

5 †Department of Chemistry, University of Toronto, 80 St. George Street, M5S 3H6, Toronto,

6 Canada

$7 \quad *$ *Corresponding Author: Email: rachel.hems@mail.utoronto.ca, Telephone: 1-416-946-7359

8 This Supporting Information provides additional text and figures including:

9 1. The emission spectrum of the Suntest CPS solar simulator

2. SOA Generation and Collection

3. Details on the oxidation reaction of benzoic acid with $\mathrm{OH}$ radicals

12 4. The effect of increasing benzoic acid concentration

5. Detailed parameters for the HPLC analysis method

6. UV-Visible spectrum of iron and pinonic acid - evidence for complexation

\section{Suntest CPS solar simulator emission spectrum}

The Suntest CPS solar simulator (Atlas), which was used to initiate Photo-Fenton chemistry, was operated with the internal cooling fan on as well as chilled by a water/ethylene glycol recirculator. The internal temperature of the reaction solutions was approximately $30-34^{\circ} \mathrm{C}$ during Photo-Fenton experiments. The emission spectrum of the solar simulator was measured with a Black-Comet C-50 spectroradiometer (StellarNet Inc.). Spectra were recorded using $10 \mathrm{~ms}$ integration time and averaged over 20 scans. Figure S1 shows the irradiance as a function of wavelength for the Suntest CPS solar simulator, measured at the location of the reaction solutions, compared to that expected of sunlight.

The spectral irradiance of sunlight was calculated over the wavelength range of 250 - 800 nm with the National Center for Atmospheric Research's “Quick TUV Calculator", available here: http://cprm.acom.ucar.edu/Models/TUV/Interactive_TUV/. 
The following parameters were used: $\mathrm{SZA}=0^{\circ}$, overhead ozone column $=300$ Dobson units, surface albedo $=0.1$, and ground elevation $=0 \mathrm{~km}$. The total downwelling radiation is presented.

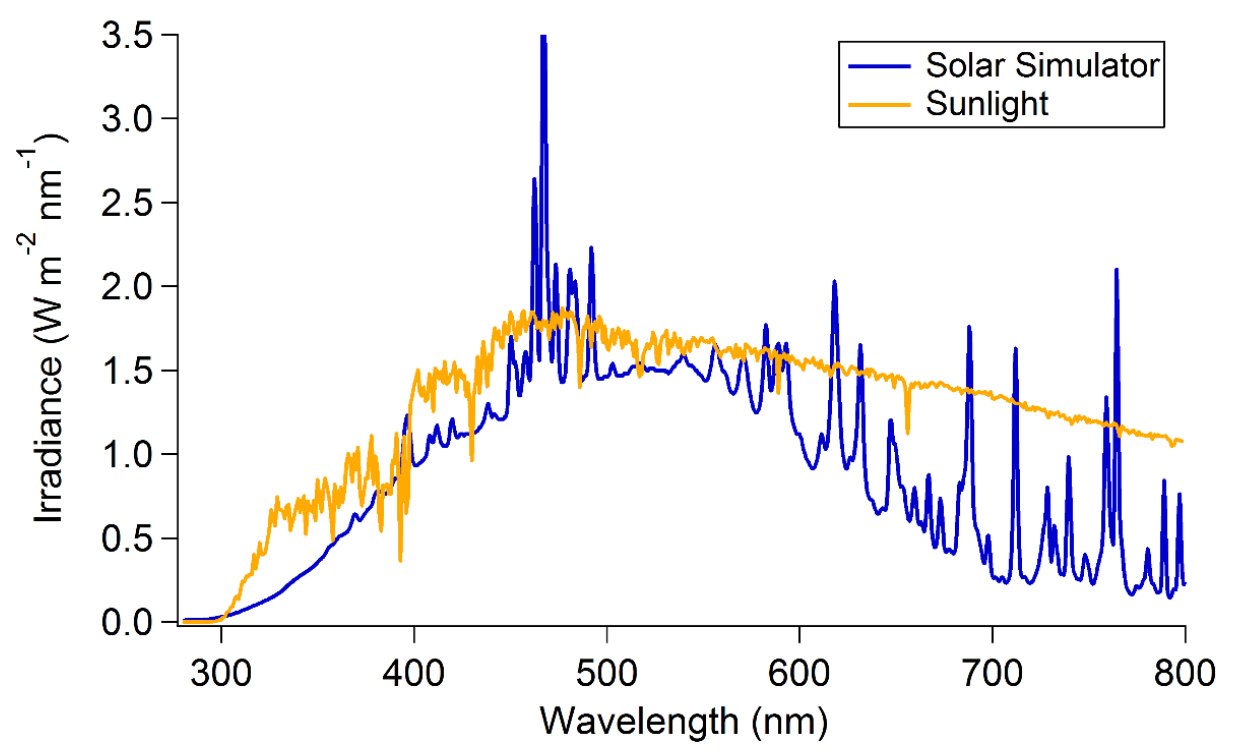

Figure S1. Irradiance as a function of wavelength for the Suntest CPS solar simulator (measured) and sunlight (calculated).

\section{SOA Generation and Collection}

SOA was generated at room temperature $(293 \pm 3 \mathrm{~K})$ from the ozonolysis of gas phase $\alpha$ pinene in a dark, $3 \mathrm{~L}$ glass flow tube reactor under dry conditions $(\mathrm{RH}<5 \%)$. $\alpha$-pinene was introduced by passing a $1.7 \mathrm{sccm}$ flow of nitrogen through a bubbler containing liquid $\alpha$ pinene (Sigma-Aldrich) held at $-10^{\circ} \mathrm{C}$, which was diluted with a $100 \mathrm{sccm}$ flow of purified air before entering the flow tube. Ozone was generated by passing a flow of purified air over a $185 \mathrm{~nm}$ mercury pen-ray lamp to reach an approximate mixing ratio of $1.9 \mathrm{ppm}$ in the flow tube, in excess of the $\alpha$-pinene mixing ratio. The total flow rate in the reactor was $1700 \mathrm{sccm}$, corresponding to a residence time of 1.76 minutes. No OH scavenger was added. SOA was collected on supported PTFE filters (Zefluor, Pall Life Sciences, $47 \mathrm{~mm}, 2 \mu \mathrm{m}$ pore size) for 48 hours, giving rise to approximately $7 \mathrm{mg}$ of material. Immediately after collecting, the water soluble fraction of SOA was extracted in $10 \mathrm{~mL}$ of purified water (18 M $\Omega$, Millipore). All reactions were carried out on the same day as collection to reduce any sample storage artefacts. The $\mathrm{pH}$ of extracted SOA solutions ranged between $3.5-4.5$. 


\section{Details on the oxidation reaction of benzoic acid with $\mathrm{OH}$ radicals}

The rate constant for the $\mathrm{OH}$ oxidation of benzoic acid is $4.3 \times 10^{9} \mathrm{M}^{-1} \mathrm{~s}^{-1}$ (under acidic conditions, $\mathrm{pH}=3.5$ - 4.5). ${ }^{1,2}$ The reaction produces three isomers of hydroxybenzoic acid: ortho-, meta-, and para-hydroxybenzoic acid, shown in Figure S2. Para-hydroxybenzoic acid (PHBA) was quantified in our study as it had good sensitivity and reproducible calibrations. In order to calculate $\mathrm{OH}$ concentrations produced from reaction, the PHBA concentration was corrected for the yield of PHBA from the reaction below, previously determined to be<smiles>O=C(O)c1ccccc1</smiles>

benzoic acid

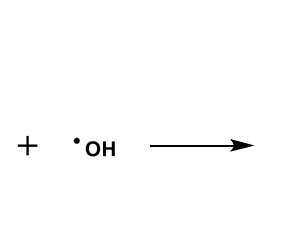

ortho-hydroxybenzoic acid

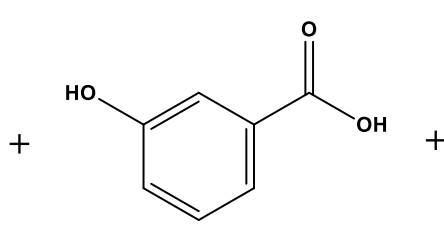

meta-hydroxybenzoic acid

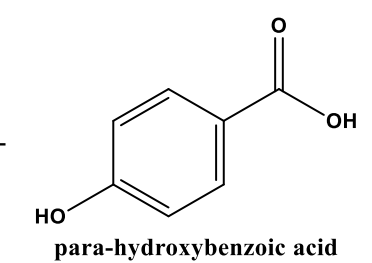

Figure S2. Reaction of benzoic acid with $\mathrm{OH}$ radical to produce ortho-, meta-, and parahydroxybenzoic acid isomers.

62

\section{The effect of increasing benzoic acid concentration}

In order to confirm that all $\mathrm{OH}$ formed from the Photo-Fenton-like reaction with $\alpha$-pinene SOA was captured, the benzoic acid (BA) concentration was increased from 1 $\mathrm{mM}$ to $3 \mathrm{mM}$ under the same reaction conditions. Figure $\mathbf{S 3}$ shows that the production of para-hydroxybenzoic acid (PHBA) and total $\mathrm{OH}$ production at lower BA concentration is consistent with increased BA concentration, within experimental uncertainty. Taking the concentration of PHBA produced, we convert it to the concentration of $\mathrm{OH}$ produced, using the known PHBA yield (18\%). ${ }^{2}$ The molar yield of $\mathrm{OH}$ from these reactions is calculated from the $\mathrm{OH}$ produced at 60 minutes of reaction time, divided by the total starting concentration of SOA material. The $\mathrm{OH}$ molar yields (in terms of SOA) for the

$\mathrm{OH}$ Molar Yield from Photo-Fenton SOA $(1 \mathrm{mM} \mathrm{BA})=0.60 \pm 0.22 \%$ 
As the absolute production of PHBA and the $\mathrm{OH}$ molar yields from both reactions agree within experimental uncertainty, we conclude that $1 \mathrm{mM} \mathrm{BA}$ is sufficient to capture all available $\mathrm{OH}$ produced from the Photo-Fenton reaction with SOA.

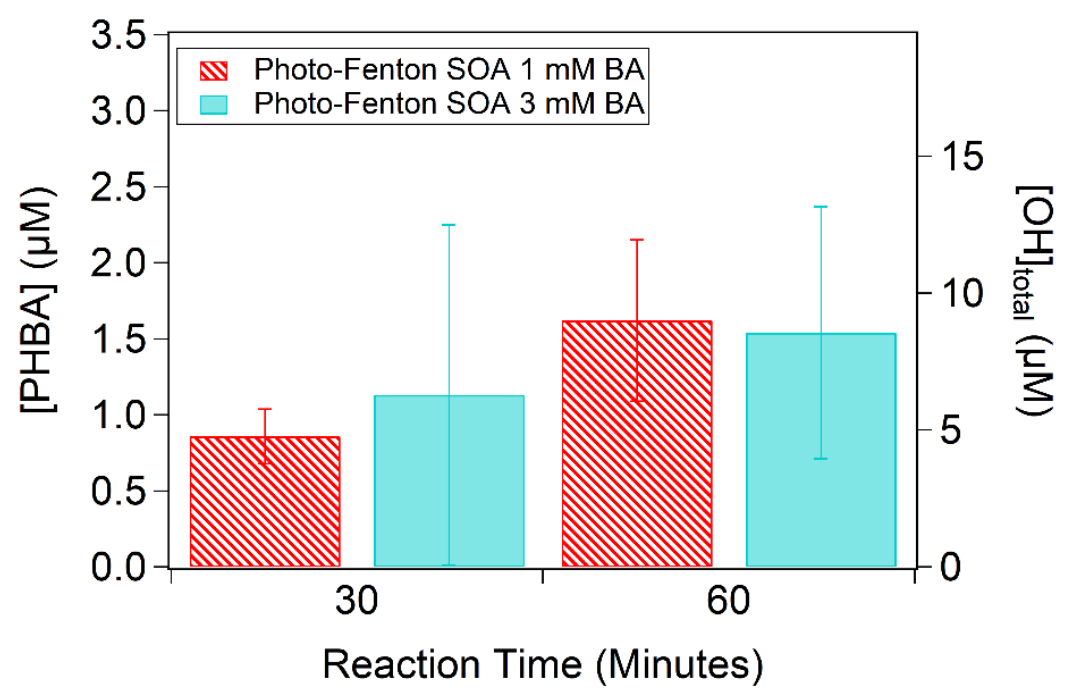

Figure S3. Para-hydroxybenzoic acid (PHBA) and total $\mathrm{OH}$ formation as a function of reaction time (time since irradiation) from the Photo-Fenton-like reaction with $\alpha$-pinene SOA with $1 \mathrm{mM}$ and $3 \mathrm{mM}$ of benzoic acid (BA) as the $\mathrm{OH}$ radical trap. Error bars indicate propagated standard deviation from multiple $(\geq 3)$ experiments and respective control reactions.

Further confirmation that all $\mathrm{OH}$ produced from the Photo-Fenton reaction with pinonic acid was captured was carried out to ensure pinonic acid was not competitively reacting with $\mathrm{OH}$. The Photo-Fenton reaction with $45 \mu \mathrm{M} \mathrm{H}_{2} \mathrm{O}_{2}$ and $1500 \mu \mathrm{M}$ pinonic acid was carried out at two benzoic acid concentrations, $1 \mathrm{mM}$ and $5 \mathrm{mM}$. Figure $\mathbf{S 4}$ shows that PHBA and total $\mathrm{OH}$ produced in these two reactions is indistinguishable within the experimental uncertainty. It is concluded that $1 \mathrm{mM}$ benzoic acid is sufficient to capture the total $\mathrm{OH}$ production from the Photo-Fenton reaction with $\mathrm{H}_{2} \mathrm{O}_{2}$ and pinonic acid. The $\mathrm{OH}$ molar yields (in terms of $\mathrm{H}_{2} \mathrm{O}_{2}$ ) for these two reactions are as follows: 


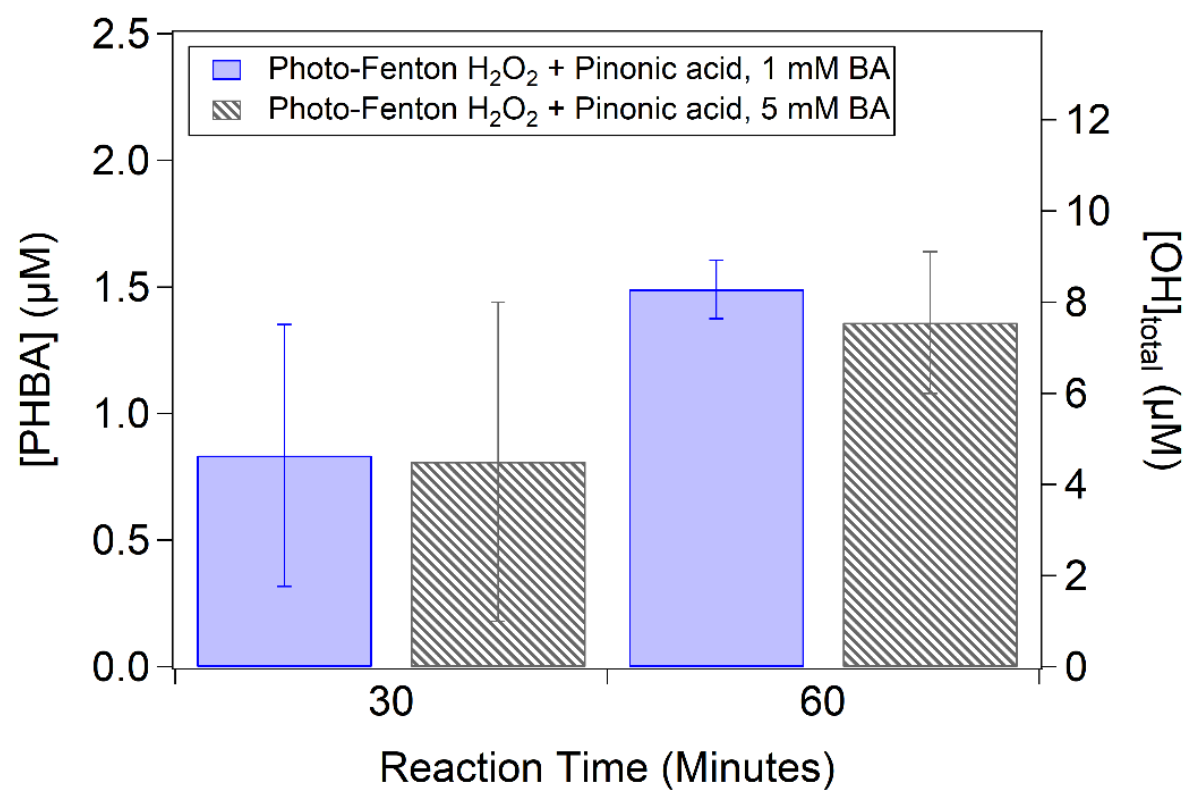

Figure S4. Para-hydroxybenzoic acid (PHBA) and total $\mathrm{OH}$ formation as a function of reaction time (time since irradiation) from the Photo-Fenton-like reaction with $\mathrm{H}_{2} \mathrm{O}_{2}$ (45 $\mu \mathrm{M})$ and pinonic acid $(1500 \mu \mathrm{M})$ with $1 \mathrm{mM}$ and $5 \mathrm{mM}$ of benzoic acid (BA) as the $\mathrm{OH}$ 105 radical trap. Error bars indicate propagated standard deviation from multiple $(\geq 3)$

\section{Detailed parameters for the HPLC analysis method}

A PerkinElmer Series 200 HPLC with Shimadzu UV-Vis detector with deuterium lamp was used for separation and quantification of benzoic acid and (ortho-, meta-, and para-) hydroxybenzoic acids (HBA). The detector wavelength was set to $256 \mathrm{~nm}$, with a range of 0.01. Separation was achieved with a Phenomenex Gemini $150 \mathrm{~mm} \mathrm{C18}$ column. The flow rate was $0.5 \mathrm{~mL} / \mathrm{min}$ with a 14.3 minute, two-step gradient elution starting with: $87 \%$ acidified water $(0.13 \% \mathrm{v} / \mathrm{v}$ trifluoroacetic acid in water) and $13 \%$ acetonitrile, linearly increasing to $35 \%$ acetonitrile from 5 to 8.3 minutes, and then returning to $13 \%$ acetonitrile for the remaining 6.5 minutes.

All samples were acidified with one drop of $1 \mathrm{mM} \mathrm{H}_{2} \mathrm{SO}_{4}$ prior to analysis. Samples were injected manually with a glass syringe, rinsed with both deionized water and acetonitrile. Peak integration was conducted in the provided TotalChrom software. Para-hydroxybenzoic acid (PHBA) eluted as a single peak at a retention time of approximately $3 \mathrm{~min}$. 
Calibrations were performed with a five-point calibration ranging from $0-1000$ $\mu \mathrm{M}$ of each of para-HBA, meta-HBA, ortho-HBA, and benzoic acid (all Sigma-Aldrich). Reported errors were calculated from the standard deviation between triplicate reaction trials.

\section{UV-Visible spectrum of iron and pinonic acid - evidence for complexation}

The UV-Vis spectrum of equimolar concentrations of Fe(II) and pinonic acid (100 $\mu \mathrm{M}$ ) was measured to investigate the possibility for iron complexation. To remove the contribution of absorbance from free pinonic acid, the spectrum for the mixture of iron and pinonic acid was normalized by subtracting the spectrum of only pinonic acid (also at $100 \mu \mathrm{M})$. Figure $\mathbf{S 5}$ shows the normalized spectrum of the iron and pinonic acid mixture compared to the spectrum of iron(II) alone (at $100 \mu \mathrm{M}$ ). There is a significant increase in the absorbance of the iron and pinonic acid mixture at lower wavelengths (approximately $230-350 \mathrm{~nm}$ ) which is indicative of complex formation between the iron and acid. The change in the electronic structure when a complex is formed is reflected in the absorbance profile for the iron-acid complex.

The measurements were made with a liquid waveguide capillary UV-Visible system (50 cm path length, World Precision Instruments), with a deuterium tungsten halogen light source (DT-Mini-2, Ocean Optics) and a temperature controlled UV-Vis spectrometer (USB2000+, Ocean Optics).

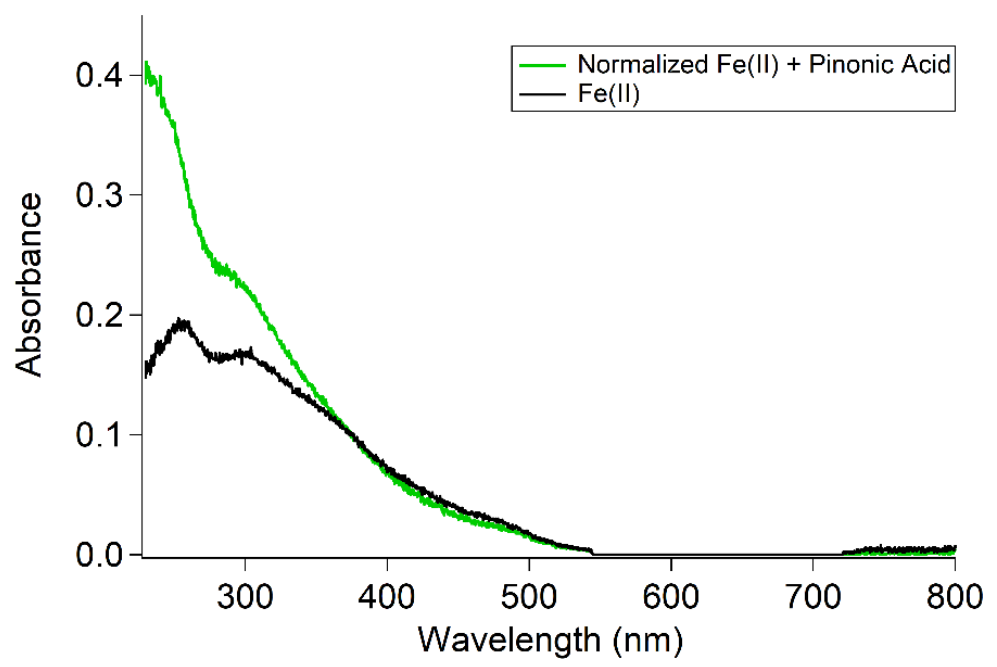

Figure S5. UV-Visible absorbance spectra of the Fe(II)-pinonic acid complex (corrected for absorbance due to free pinonic acid) and $\mathrm{Fe}($ II) alone. 
142

143

144

145

146

147

148

\section{References}

(1) Wander, R.; Neta, P.; Dorfman, L. M. Pulse Radiolysis Studies. XII. Kinetics and Spectra of the Cyclohexadienyl Radicals in Aqueous Benzoic Acid Solution. J. Phys. Chem. 1968, $72(8), 2946-2949$.

(2) Anastasio, C.; Mcgregor, K. G. Chemistry of fog waters in California's Central Valley: 1. In situ photoformation of hydroxyl radical and singlet molecular oxygen. Atmos. Environ. 2001, 35, 1079-1089. 